\title{
Difficulties in Residency: An Examination of Clinical Rotations and Competencies Where Family Medicine Residents Most Often Struggle
}

\author{
Orysya Svystun, MD, BSc; Shelley Ross, PhD
}

\begin{abstract}
BACKGROUND AND OBJECTIVES: Remediation in residency is expensive; however, most research has focused on general approaches to remediation, with minimal investigation into whether there are patterns to the competencies or rotations that are most difficult for residents. Acquiring this information may improve future physician training and potentially reduce the frequency of resource-intensive remediation. We aimed to determine the competencies and rotations most challenging for family medicine residents, as defined by the number of assessments with flags (one or more competencies indicated as less than satisfactory).
\end{abstract}

METHODS: A secondary data analysis of archived resident files from a large Canadian family medicine residency program was conducted. Residents from six cohorts were reviewed $(\mathrm{N}=393)$ and flags on the in-training evaluation reports (ITERs) and summative periodic progress reports were recorded and summarized with descriptive statistics.

RESULTS: One hundred forty-one residents (36\%) received at least one flag during training. Rotations where learners received the most flags were: internal medicine (average 1.52 \pm 4.82 flags), urban family medicine (average $1.48 \pm 4.18$ ), and obstetrics (average 1.07 \pm 3.80 ). For residents having at least one flag, competencies causing most difficulty included: professionalism (21.4\%), clinical decision making (17.8\%), and teamwork and communication (15.5\%).

CONCLUSIONS: The file review identified coronary care unit, internal medicine, obstetrics, and general surgery as those rotations (adjusted for length) where family medicine residents most often struggled. Furthermore, deficient clinical knowledge was not one of the main reasons that residents are flagged. These findings may inform programs about where to target resident supports and resources.

(Fam Med. 2018;50(8):613-6.)

doi: 10.22454/FamMed.2018.794779

D) esidency programs strive to educate competent, efficient, and safe graduates. Despite best efforts, $2 \%$ to $9 \%$ of residents require remediation. ${ }^{1-6}$ Unfortunately, there is limited research exploring the specific competencies or rotations that are most challenging for family medicine trainees. Prior studies, few of which analyzed family medicine residents, were limited by relying on anonymous reports from program directors, ${ }^{7-9}$ or were smallscale reviews. $^{4-6}$
To address the existing literature gap on the areas of difficulty for family medicine residents, we conducted a retrospective file review in a midsized Canadian training program. We examined in-training assessment reports (ITERs-summative end-ofrotation assessments of resident progress) for six cohorts of residents to identify in which rotations family medicine residents were most likely to get a flagged ITER (flag=less than satisfactory overall judgment of competence). An understanding of the competencies and rotations where family medicine residents struggle may allow programs to better target teaching resources, consequently reducing the number of residents undergoing resource intensive remediation.

\section{Methods}

Before beginning the study, ethics approval was obtained, the file reviewer signed a confidentiality agreement, and files were deidentified. Six consecutive cohorts from a Canadian family medicine 2-year training program were included (rural and urban streams).

Data came from two sources. From the resident assessment files we extracted the start and graduation dates, gender, if remediation

From the Department of Family Medicine, University of Alberta, Edmonton, AB, Canada. 
ensued and what it entailed (specifically, what competencies were identified for remediation), and whether the resident went to a Canadian or US medical school (CMG) or an international medical school (IMG). From the in-training evaluation reports (ITERs) and the summative progress reports, we collected the following: total flagged (below average) items, below average competencies, and flags per rotation.

Extracted information regarding difficulties was coded for analysis using Sentinel Habits (a competency framework implemented in the target program) and the CanMEDS roles as guides. ${ }^{10,11}$ Descriptive statistics were used to summarize our findings.

\section{Results}

From six cohorts, 393 files were reviewed, none were excluded. Of the residents whose files were reviewed, 207 were female (53\%). Our participant demographics for the full dataset are shown in Table 1. A total of 141 trainees $(36 \%)$ had at least one flag. The remediation rate was $4.3 \%$, with 17 residents having remediation contracts in their files.

Rotations where residents received the most flags were internal medicine, followed by urban family medicine, and obstetrics, where one resident accumulated 40 flags (Table 2). In looking at numbers of flags adjusted for length of rotation ("Rate of flags," Table 2), the rotations where family medicine residents received the most flags were coronary care unit, internal medicine, obstetrics, and general surgery.

Among residents with flags, 84 (59.6\% of the residents with at least one flag) scored below average on professionalism at least once, 70 (49.6\%) on clinical decision making, $61(43.3 \%)$ on teamwork and communication, $48(34.0 \%)$ on clinical knowledge, and $43(30.5 \%)$ showed deficiencies in evidence-based medicine (Table 3).

\section{Discussion}

To our knowledge this is the largest study dedicated to family medicine training difficulties. A previous study by Reamy and Harman included 230 residents from a 25 -year period. ${ }^{6}$ Their file review was conducted at a single family medicine program and no sample gender preponderance was described. The remediation rate of $4.3 \%$ in our cohort is consistent with literature reported values of $2 \%$ to $9 \% .^{1-6}$ Further, the demographics of the residents in this study (Table 1) are comparable to other family medicine residency programs in Canada (see annual reports from the Canadian Post-MD Education Registry, www.caper.ca/ en/post-graduate-medical-education/ annual-census). Finally, family medicine residency training in Canada is accredited by the College of Family Physicians of Canada, and is relatively consistent across Canada in terms of the clinical rotations and experiences that are offered.

In the subject residency program, internal medicine, family medicine, and obstetrics rotations resulted in the most flags. In the studied program, internal medicine is 8 weeks, yet it generated as many flags as the 16 - to 20 -week family medicine rotation. The emergency block, although as long as internal medicine, produced half the flags. Accounting for its duration, the coronary care unit-a 4-week rotation-is the service where family medicine residents are most likely to encounter difficulty, followed by internal medicine, obstetrics, and general surgery (Table 2 ). The rotations that are challenging for family medicine residents are underinvestigated in literature; however, emergency medicine is the service that detects most problem medical students. ${ }^{12}$ This is contrary to our study, where emergency medicine did not pose difficulties for family medicine learners.

Table 1: Demographics of Residents Whose Files Are Included in the Full Dataset, Including the Subset of Data for Those Residents With Flagged Assessments

\begin{tabular}{|l|c|c|}
\hline & Overall Dataset & Residents With Flagged Assessments \\
\hline Total files reviewed & 393 & $141(36 \%$ of total files included in study) \\
\hline Male & $181(46 \%)$ & $64(45 \%)$ \\
\hline Female & $207(53 \%)$ & $77(54 \%)$ \\
\hline Sex not indicated in file & $5(1 \%)$ & n/a \\
\hline Canadian or United States medical graduates & $284(72 \%)$ & $85(60 \%$ of those with flags; $30 \%$ of total CMG \\
residents $)$
\end{tabular}

\footnotetext{
* Defined as residents who went to medical school in countries other than Canada or the United States.
} 
Table 2: Rotations Where Family Medicine Residents Received Flagged Assessments, Indicating the Overall Average Number of Flags and the Mean Rate of Flags (Based on Length of Rotation)

\begin{tabular}{|c|c|c|c|}
\hline Rotation & $\begin{array}{c}\text { Overall Flags* } \\
\text { (Mean士SD, Range) }\end{array}$ & Length of Rotation & Rate of Flags \\
\hline Internal medicine & $1.52 \pm 4.82(0,31)$ & 8 weeks & 0.19/week \\
\hline Urban family medicine & $1.48 \pm 4.18(0,32)$ & $16-20$ weeks & 0.09/week \\
\hline Obstetrics & $1.07 \pm 3.80(0,40)$ & 8 weeks & $0.13 /$ week \\
\hline Coronary care unit & $0.81 \pm 2.07(0,12)$ & 4 weeks & $0.20 /$ week \\
\hline Rural family medicine & $0.62 \pm 2.17(0,13)$ & 6 weeks & 0.10/week \\
\hline Pediatrics & $0.56 \pm 1.49(0,9)$ & 8 weeks & 0.07/week \\
\hline General surgery & $0.49 \pm 2.24(0,20)$ & 4 weeks & $0.12 /$ week \\
\hline Emergency & $0.25 \pm 1.54(0,17)$ & 8 weeks & 0.03/week \\
\hline Palliative care & $0.18 \pm 1.00(0,11)$ & variable & variable \\
\hline $\begin{array}{l}\text { Remaining mandatory rotations: } \\
\text { Rheumatology } \\
\text { Orthopedics } \\
\text { Dermatology } \\
\text { Anesthesia } \\
\text { Care of the elderly (geriatrics) } \\
\text { Public health } \\
\text { Psychiatry } \\
\text { Intensive care unit }\end{array}$ & $\begin{array}{c}\text { (average flags were fewer } \\
\text { than } 0.10 \text { ) }\end{array}$ & variable & variable \\
\hline
\end{tabular}

* Average number calculated based on N=141 (residents with at least one flag).

Table 3: Competencies Indicated as Areas of Concern for Family Medicine Residents on Assessments With at Least One Flag

\begin{tabular}{|l|c|}
\hline \multicolumn{1}{|c|}{ Domain } & Number of Residents With Flags (\%) \\
\hline Demonstrates respect and responsibility (professionalism) & $84(59.6)$ \\
\hline Clinical decision making & $70(49.6)$ \\
\hline Teamwork and communication & $61(43.3)$ \\
\hline Clinical knowledge & $48(34)$ \\
\hline Evidenced-based medicine & $43(30.5)$ \\
\hline Awareness of personal limitations & $39(27.7)$ \\
\hline Helps others learn & $31(22)$ \\
\hline Technical and procedural skills & $28(19.9)$ \\
\hline Physical exam skills & $26(18.4)$ \\
\hline Patient management & $24(17.0)$ \\
\hline Generates relevant hypothesis (clinical reasoning) & $24(17.0)$ \\
\hline Other & $13(9.2)$ \\
\hline Applies ethical principles & $11(7.8)$ \\
\hline Promotes effective practice quality & $11(7.8)$ \\
\hline Motivation & $9(6.4)$ \\
\hline Performance under stress & $3(2.1)$ \\
\hline
\end{tabular}

* Percentage calculated based on residents who received at least one flag $(\mathrm{N}=141)$. 
Professionalism was identified as the main concern $59.6 \%$ of residents with flags had below average performance in this area) when exploring competencies most likely to be flagged. Clinical decision making (49.6\%), teamwork and communication $(43.3 \%)$, and clinical knowledge (34.0\%) followed thereafter (Table 3). Similar values were reported in a number of prior studies. ${ }^{4,7-9}$ For example, a United States survey of internal medicine residency program directors revealed that $53 \%$ of trainees encountered difficulty with patient care, $47.9 \%$ struggled with medical knowledge, and over $40 \%$ with professionalism, organization, and prioritization. ${ }^{8}$ Inappropriate interactions were the most prevalent concern amongst problem neurology residents. ${ }^{7}$ Herman and Reamy identified knowledge deficiencies as most frequent among family medicine residents, followed by attitudinal issues and interpersonal difficulties. ${ }^{6}$ The findings of this study are comparable to those in the context of anesthesia residency training programs, where Turner et al described professionalism as the dominating precipitant of resident probation. ${ }^{5}$

These findings benefit training programs by giving guidance regarding clinical areas where learners may need extra support. However, it may be more difficult to address professionalism and interpersonal deficiencies. ${ }^{13,14}$ Future avenues of investigation may be identifying the success of remediation specific to individual competencies. In addition, differences in areas of difficulty between the international and local medical graduates may be explored.

The importance of knowing the rotations where residents are more likely to be flagged lies in understanding which rotations pose difficulty for family medicine residents in particular. There may be specific knowledge or skills needed for those rotations that can be taught to residents before those rotations to ensure that the learning experience is maximized. Or, a rotation may be demanding in ways that highlight a competency gap that has not otherwise been identified (professionalism, communication, working in a team, etc). This knowledge may be used by programs to consider certain rotations as being more sensitive in catching deficiencies in resident competencies.

The study's primary limitation is that it was conducted in the context of one program; as a result, some of the findings may not be generalizable. This limitation, however, was also present in the only other large family medicine file review. ${ }^{6}$ Another issue to note is that, given the limits of a brief report, we have not addressed the higher rate of flagged assessments among IMGs; however, this is an area ripe for further research.

\section{Conclusion}

To date, this is the largest retrospective file review specifically examining data from family medicine residents. Our findings indicate that certain rotations may be more likely to identify potential gaps in resident competencies; in this study, the coronary care unit and internal medicine rotations are where most trainees encounter difficulty when accounting for the duration of the rotation. In line with previous literature, we found that residents often struggle with the nonknowledge areas of medicine. Programs may be able to use the assessments from certain rotations as "canary in the coal mine" indicators of gaps in resident competence that may not have been identified elsewhere. Identifying these gaps can allow programs to address potential problem areas with residents more efficiently, potentially avoiding the costly remediation process.

ACKNOWLEDGMENTS: Funding for Orysya Svystun was provided by Health Professions Summer Studentship, University of Alberta Faculty of Medicine \& Dentistry, and the University of Alberta Department of Family Medicine.

Presentations: Preliminary findings from this project were presented in a poster format at the North American Primary Care Research Group Annual Meeting, Cancun, Mexico, October, 2015, and at the Canadian Conference of Medical Education, Montreal, QC, Canada, April, 2016. An oral presentation was given at the Alberta Scientific Assembly. Banff, AB, Canada, March, 2016.

CORRESPONDING AUTHOR: Address correspondence to Dr Shelley Ross, 6-10 University Terrace, Edmonton, AB, Canada, T6G 2T4. shelley.ross@ualberta.ca.

\section{References}

1. Christensen MK, O’Neill L, Hansen DH, Norberg K, Mortensen LS, Charles P. Residents in difficulty: a mixed methods study on the prevalence, characteristics, and sociocultural challenges from the perspective of residency program directors. BMC Med Educ. 2016;16(1):69.

2. Bhatti NI, Ahmed A, Stewart MG, Miller $\mathrm{RH}$, Choi SS. Remediation of problematic residents-A national survey. Laryngoscope. 2016;126(4):834-838

3. Silverberg M, Weizberg M, Murano T, Smith JL, Burkhardt JC, Santen SA. What is the prevalence and success of remediation of emergency medicine residents? West J Emerg Med. 2015;16(6):839-844.

4. Zbieranowski I, Takahashi SG, Verma S, Spadafora SM. Remediation of residents in difficulty: a retrospective 10 -year review of the experience of a postgraduate board of examiners. Acad Med. 2013;88(1):111-116.

5. Turner JA, Fitzsimons MG, Pardo MC Jr, et al. Effect of performance deficiencies on graduation and board certification rates: $\mathrm{A} 10-\mathrm{yr}$ multicenter study of anesthesiology residents. Anesthesiology. 2016;125(1):221-229.

6. Reamy BV, Harman JH. Residents in trouble: an in-depth assessment of the 25-year experience of a single family medicine residency. Fam Med. 2006;38(4):252-257.

7. Tabby DS, Majeed MH, Schwartzman RJ. Problem neurology residents: a national survey. Neurology. 2011;76(24):2119-2123.

8. Dupras DM, Edson RS, Halvorsen AJ, Hopkins RH Jr, McDonald FS. "Problem residents": prevalence, problems and remediation in the era of core competencies. Am J Med. 2012;125(4):421-425.

9. Riebschleger MP, Haftel HM. Remediation in the context of the competencies: a survey of pediatrics residency program directors. J Grad Med Educ. 2013;5(1):60-63.

10. The family medicine milestone project. J Grad Med Educ. 2014;6(1)(suppl 1):74-86.

11. Ross S, Poth CN, Donoff M, et al. Competency-based achievement system: using formative feedback to teach and assess family medicine residents' skills. Can Fam Physician. 2011;57(9):e323-e330.

12. Aram N, Brazil V, Davin L, Greenslade J. Intern underperformance is detected more frequently in emergency medicine rotations. Emerg Med Australas. 2013;25(1):68-74.

13. Cruess SR, Cruess RL. Teaching professionalism-why, what and how. Facts Views Vis Obgyn. 2012;4(4):259-265

14. Ginsburg S, Regehr G, Mylopoulos M. From behaviours to attributions: further concerns regarding the evaluation of professionalism. Med Educ. 2009;43(5):414-425. 